\title{
Inhalation of Carbon Black Nanoparticles Aggravates Pulmonary Inflammation in Mice
}

\author{
Devina Saputra ${ }^{1,2,+}$, Jin-ha Yoon ${ }^{3, \dagger}$, Hyunju Park', Yongju Heo', Hyoseon Yang ${ }^{1}$, Eun Ji Lee', \\ Sangjin Lee ${ }^{1}$, Chang-Woo Song' and Kyuhong Lee ${ }^{1,2}$ \\ ${ }^{1}$ Inhalation Toxicology Center, Korea Institute of Toxicology, Jeonbuk, Korea \\ ${ }^{2}$ Toxicology and Pharmacology, Korea University of Science and Technology, Daejeon, Korea \\ ${ }^{3}$ Institute for Occupational Health, Yonsei University College of Medicine, Seoul, Korea
}

(Received March 14, 2014; Revised June 2, 2014; Accepted June 15, 2014)

\begin{abstract}
An increasing number of recent studies have focused on the impact of particulate matter on human health. As a model for atmospheric particulate inhalation, we investigated the effects of inhaled carbon black nanoparticles (CBNP) on mice with bleomycin-induced pulmonary fibrosis. The CNBPs were generated by a novel aerosolization process, and the mice were exposed to the aerosol for 4 hours. We found that CBNP inhalation exacerbated lung inflammation, as evidenced by histopathology analysis and by the expression levels of interleukin- 6 protein, fibronectin, and interferon- $\gamma$ mRNAs in lung tissues. Notably, fibronectin mRNA expression showed a statistically significant increase in expression after CBNP exposure. These data suggest that the concentration of CBNPs delivered (calculated to be $12.5 \mu \mathrm{g} / \mathrm{m}^{3}$ ) can aggravate lung inflammation in mice. Our results also suggest that the inhalation of ultrafine particles like PM 2.5 is an impactful environmental risk factor for humans, particularly in susceptible populations with predisposing lung conditions.
\end{abstract}

Key words: Lung inflammation, Ultrafine particle, Carbon black nanoparticles, Inhalation toxicity

\section{INTRODUCTION}

Recently, concerns about the inhalation risks of ultrafine particles have increased, given their wider chemical, electronic, and medicinal applications as well as the continued development of new nanotechnologies. Concurrently, the amount of ultrafine particulate matter (PM 2.5) in the atmosphere is gradually rising, with the general population being exposed more and more $(1,2)$. Ultrafine particles are partic-

Correspondence to: Kyuhong Lee, Inhalation toxicology research center, Korea Institute of Toxicology, 30, Baekhak 1-Gil, Jeongeupsi, Jeollabuk-do 580-185, Korea

E-mail: khlee@kitox.re.kr, khleekit@gmail.com

${ }^{\dagger}$ These authors contributed equally to this work.

Abbreviations: CBNPs, carbon black nanoparticles; BLM, bleomycin; PM 2.5, particulate matter $\leq 2.5$ microns; IPF, idiopathic pulmonary fibrosis; SNPS, scanning nanoparticle spectrometer; FN, fibronectin; H\&E, hematoxylin and eosin; IFN- $\gamma$, interferon- $\gamma$; IL-6, interleukin-6.

This is an Open-Access article distributed under the terms of the Creative Commons Attribution Non-Commercial License (http:// creativecommons.org/licenses/by-nc/3.0) which permits unrestricted non-commercial use, distribution, and reproduction in any medium, provided the original work is properly cited. ularly concerning given their small size, which generally equates to a larger effective surface area and higher toxicity $(1,3)$. Inhaled nanoparticles have been linked to a number of biologic pathologies, including inflammation, fibrosis, genotoxicity, and carcinogenicity (4-6). Titanium dioxide and carbon black are two types of ultrafine particles that have been commonly used to evaluate the risk of nanoparticle inhalation (7).

Carbon black is a type of ultrafine carbon particle, which is a major component of the soot generated by incomplete fuel combustion $(5,8)$. It is also a core component of many ultrafine pollutants like diesel exhaust (9). Carbon black is used commercially as a black ink pigment, a paint, plastic, and as a reinforcing agent for tires and other rubber goods (10). Unfortunately, carbon black emissions into the atmosphere have continued to rise, with current estimates of carbon black emissions in India and China reaching two to three times higher than previously thought. Consequently, the evaluation of the human health risks of carbon black emissions is becoming more critical.

One method for evaluating the toxicity of inhaled pollutants is a mouse model, in which pulmonary fibrosis is induced by the glycopeptide antibiotic bleomycin (BLM). In humans, BLM can induce severe respiratory injury, 
including lung fibrosis, while in a number of animal species, it causes alveolar injury that triggers an alveolar repair response (11). The model has been utilized to evaluate the pathology of fibrosis and lung injury, also to test the efficacy of potential treatments $(12,13)$. In one study, this model was used to investigate idiopathic pulmonary fibrosis (IPF), a serious, chronic, and progressive type of pulmonary fibrosis for which the survival rate is only $20 \sim 30 \%$ within 5 years of diagnosis. The average survival rate of IPF is only 3 years from diagnosis if not treated properly (13-15). During the terminal stage of IPF, the lungs essential cease to function due to severe fibroblastic proliferation and accumulation of extracellular matrix (13).

Herein, we utilized the BLM-induced pulmonary fibrosis model to evaluate the complications of respiratory conditions caused by carbon black nanoparticles (CBNPs). CBNPs are amorphous, spherical particles of carbon black that are poorly water-soluble. CBNPs are thought to aggravate several respiratory diseases in humans, including lung inflammation and fibrosis $(5,14,16)$. Consequently, the mouse pulmonary fibrosis model studied herein is an excellent model for evaluating the possible human health effects of ultrafine particle pollutants, particularly in populations that suffer from lung disease.

\section{MATERIALS AND METHODS}

Animal protocols. All experiments were approved by the Institutional Animal Care and Use Committee and were conducted in accordance with international guidelines established by the Association for Assessment and Accreditation of Laboratory Animal Care. Male 7-week-old C57BL/6 mice were purchased from Orient Bio Inc. (Seongnam, Korea) and were housed in a pathogen-free environment maintained at $19 \sim 26^{\circ} \mathrm{C}$ and $50 \pm 10 \%$ relative humidity with a $12 \mathrm{hr}$ light-dark cycle. The mice were provided with rodent chow (PMI Lab Diet, USA) and UV-irradiated tap water ad libitum and were acclimatized for at least one week prior to beginning the study.

Generation of carbon black nanoparticles. Carbon black nanoparticles (CBNPs) were generated by an electric arc discharge system using a carbon generator (GFG-1000, Palas GmbH, Germany). The carbon generator utilized an electrical discharge between two graphite electrodes to generate ultrafine carbon black particles. To minimize carbon oxidation during the generation process, an argon stream was focused through a narrow slit into the space between the electrodes. The carbon evaporated by the electrical spark is then transported by the argon flow into a condenser that yields primarily ultrafine particles that can coagulate to larger agglomerates, depending on their concentration. The conditions used herein to generate generation carbon black nanoparticles included a flame frequency of $100 \mathrm{~s}^{-1}$ with argon gas and dried clean airflow at 1.0 bar.
Monitoring and characterization of carbon black nanoparticles. The size distribution of the CBNPs was measured in real-time using a scanning nanoparticle spectrometer with a detection range of $0 \sim 10^{7}$ particles $/ \mathrm{cm}^{3}$ (SNPS, HCT). The total CBNP concentration (number of particles per $\left.\mathrm{cm}^{3}\right)$ and size distribution $(\mathrm{dN} / \mathrm{dLogDp})$ ranged from 7.9 to $300 \mathrm{~nm}$ throughout the time during which mice were exposed. The mass concentration of CBNPs was also repeatedly measured using a gravitational method. Specifically, CBNPs were collected onto a microglass fiber filter coated with fluorocarbon $(25 \mathrm{~mm} ø$, Pallflex) for $2 \mathrm{hrs}$ with a $1 \mathrm{~L} / \mathrm{min}$ flow rate using a sampling pump (XR5000, SKC). Once collected, the mass concentration of CBNPs $\left(\mu \mathrm{g} / \mathrm{m}^{3}\right)$ was determined by weighing. Before and after weighing, each filter was equilibrated in a desiccator for at least $24 \mathrm{hrs}$ at a stabilized temperature $\left(22 \sim 23^{\circ} \mathrm{C}\right)$ and relative humidity (45 50\%).

Experimental design. BLM was purchased from Nippon Kayaku (Tokyo, Japan). Eight-week-old mice were divided into 3 groups of 6 mice as follows: vehicle control group (saline + clean air), BLM-treated control group (BLM + clean air), and BLM-treated and CBNP-exposed group. On day 1 , all mice were anesthetized with isoflurane and administered a 50-ml intratracheal dose of saline (group 1) or BLM $1 \mathrm{mg} / \mathrm{kg}$ (groups 2 and 3). Beginning on day 5 , mice were exposed to either clean air or CBNPs for $4 \mathrm{hrs}$. On day 7, mice were sacrificed, and lung samples and bronchioalveolar lavage (BAL) fluid were collected. Throughout the study, clinical symptoms and mortality were recorded daily. Body weights were recorded at the time of purchase, on the day of grouping, before intratracheal instillation, before inhalation exposure, and before necropsy.

Collection and total cell count of BAL fluid. To collect BAL fluid, mice were anesthetized with isoflurane, the trachea was cannulated, and the lung lavage was obtained by washing 3 times with $1 \mathrm{ml}$ of sterile $0.9 \%$ saline. Samples were centrifuged at 3,000 rpm for $10 \mathrm{~min}$, and the pellets were resuspended in sterile $0.9 \%$ saline, after which the total cell count was determined with an automated cell viability analyzer (Vi-CELLTM, Beckman Coulter). The resuspended pellets were then centrifuged using a Shandon Cytospin 4 (Thermo, USA). Differential cell counts were evaluated at a magnification of $\times 1000$ by light microscopy (BX51, Olympus, Tokyo, Japan) by counting 300 cells stained with Wright-Giemsa.

Measurement of cytokine level in BAL fluid. The presence of inflammatory mediators in the BAL fluid was analyzed by enzyme-linked immunosorbent assay (ELISA). The levels of interleukin-6 (IL-6) were measured using commercially available ELISA kits (R\&D Systems, USA) according to the manufacturer's protocol. 
Isolation of RNA. A portion of the lung samples was homogenized in Trizol reagent (Invitrogen, Carlsbad, CA, USA), and the isolated total RNA was repurified using an RNeasy mini kit (Qiagen, Valencia, CA, USA) according to the manufacturer's protocol. Total RNA was quantified using a NanoDrop spectrophotometer (NanoDrop Technologies, Montchanin, DE, USA), and the quality of RNA was evaluated using a 2100 Bioanalyzer (Agilent Technologies, Palo Alto, CA, USA) prior to DNA chip analyses.

Quantitative real-time reverse transcription-PCR. Gene transcripts were detected and quantified using SYBR Green (QuantiTect SYBR Green PCR Master Mix; Qiagen) according to the manufacturer's instructions on a Rotor-Gene 6000 real-time rotary analyzer (Corbett Research, Sydney, Australia). Primers were designed using the Primer3 software (http://frodo.wi.mit.edu/). A melting curve analysis was performed on all amplified products to ensure the specificity and integrity of the PCR products. The transcript level of the beta-actin gene was used as an internal standard, and fold changes were calculated according to the $2^{-\Delta \Lambda C T}$ method (9).

Histological examination. After sacrifice, mouse lungs were inflated with $10 \%$ neutral buffered formalin, after which the trachea was tied off. The lungs were then harvested, fixed with $10 \%$ neutral buffered formalin for 1 week, and embedded in paraffin. Sections 3 4- $\mu \mathrm{m}$ thick were cut and stained with hematoxylin and eosin (H\&E) for histological examination and with Masson's trichrome for examination of fibrotic changes in adjacent sections. The stained sections of each tissue specimen were evaluated at a magnification of $\times 100$ by light microscopy (BX51, Olympus, Tokyo, Japan). For inflammatory cell count, the tissue specimen ( $\mathrm{n}=3$ per group) were evaluated for macrophage, neutrophil, eosinophil, lymphocyte at a magnification of $\times 400$ by light microscopy (BX51, Olympus, Tokyo, Japan).

Statistics. Statistical analyses were performed using GraphPad Prism 3.0 (San Diego, California, USA). All results are expressed as a mean \pm standard error (SE). An analysis of variance (ANOVA) test was used to evaluate the significance of any differences between test groups. Dunnett's multiple comparison test was used to compare the control group (VC) with experimental groups, and Bonferroni's multiple comparison test was used to compare the BLM-treated, CBNPexposed group (BLM + CBNPs) to the BLM-treated control group (BC). The level of significance was set at $p<0.05$.

\section{RESULTS}

Carbon nanoparticle generation and particle characterization. The geometric mean diameter (GMD), geometric standard deviation (GSD), and total number concen-
(A)

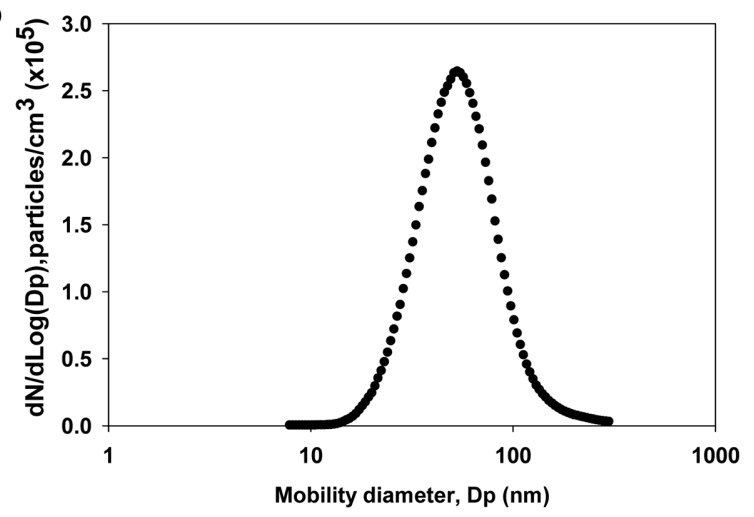

(B)

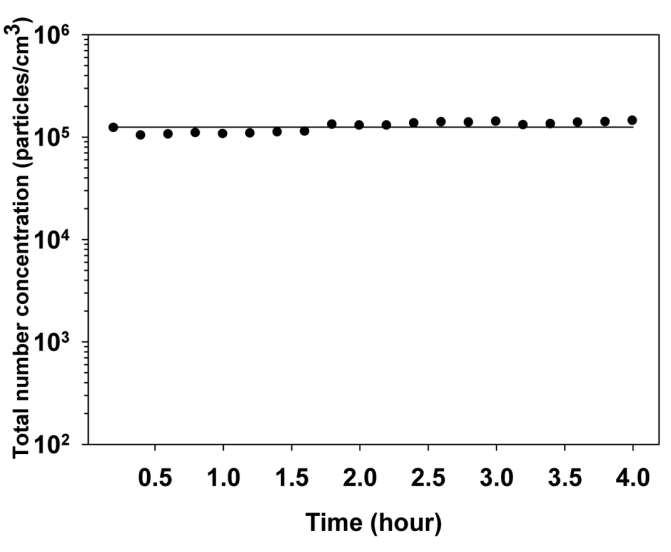

(C)

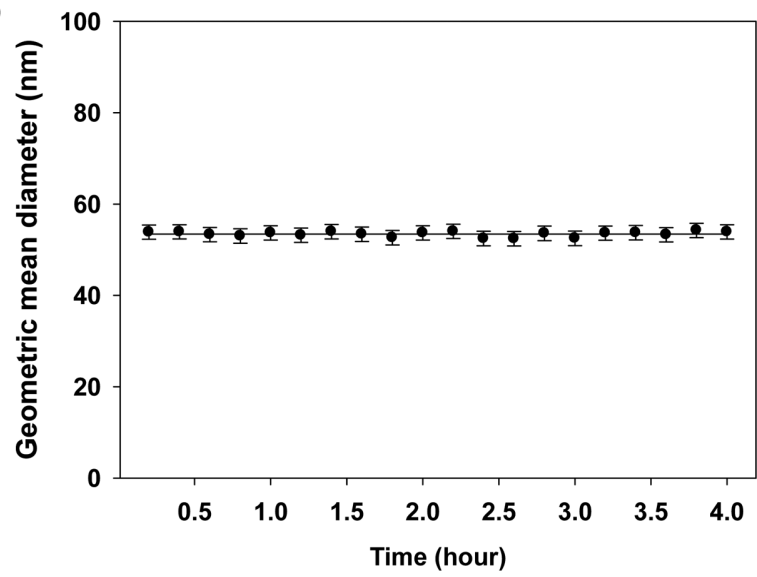

Fig. 1. (A) Size distribution of carbon black nanoparticles, loglinear scale. Variation in total number concentration, GMD, GSD of carbon black nanoparticles with time; (B) total number concentration, (C) geometric mean diameter, and (D) geometric standard deviation.

tration of the CBNPs were measured. $\mathrm{dN} / \mathrm{dLog}(\mathrm{Dp})$ is particle concentration present according to aerosol diameter $(\log )$. Particle distribution in Fig. 1A showed that CBNPs generated is below $100 \mathrm{~nm}$ following normal distribution. The mass concentration measured by filter collection was 12.5 $\mathrm{mg} / \mathrm{m}^{3}$. The CBNPs was stably generated overtime with total concentration, GMD, and GSD were $1.25 \times 10^{5}$ particles $/ \mathrm{cm}^{3}, 53 \mathrm{~nm}$, and 1.57 (Fig. 1B and Fig. 1C). 


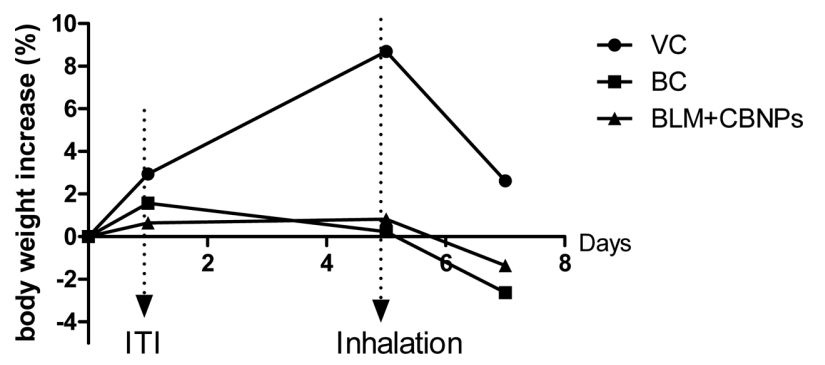

Fig. 2. Body weight changes by treatment group.

Body weight. Animal body weight was recorded. BLM instilled mice showed decrease in body weight gain compared to control group (Fig. 2). After inhalation of clean air in control group and BLM control group, also carbon black inhalation in BLM instilled mice, all groups showed body weight decrease.

Histopathological determination of lung fibrosis symptoms after treatment. The impact of CBNPs on BLMinduced lung fibrosis was assessed by histopathological evaluation (Fig. 3 and Table 1). Significant inflammatory cell infiltration and epithelial cell hyperplasia were observed in lung samples from both the BLM control group (BC) and the BLM CBNP-exposed group (BLM + CBNPs). Significant infiltration of neutrophil, macrophage, and mononuclear cells was observed around the bronchiole and in perivenular and alveolar spaces. Overall, the extent of inflammation and hyperplasia was minimal to moderate, but the extent of the symptoms was significantly higher in the BLM exposed group compared to the BLM control group.

Determination of total cell counts from BAL fluid and differential cell count from histopathology. The total cell counts in BAL samples were $0.262 \times 10^{6}$ cells $/ \mathrm{ml}$, $0.954 \times 10^{6}$ cells $/ \mathrm{ml}$, and $0.977 \times 10^{6}$ cells $/ \mathrm{ml}$ for the control group, the BLM control, and the BLM exposed group, respectively (Fig. 4). Thus, BLM treatment and with or without CBNP exposure significantly increased the BAL cell count compared to the control group. Inflammatory cell count is showed in Fig. 6. Macrophage and neutrophil number were significantly increased after CBNP exposure in BLM model, while lymphocyte and eosinophil number were not significantly different compared to BLM control group.

\section{Measurement of protein and mRNA expression levels} in the lungs. To evaluate whether CBNP exposure induced an inflammatory response, we evaluated proinflammatory
(A)

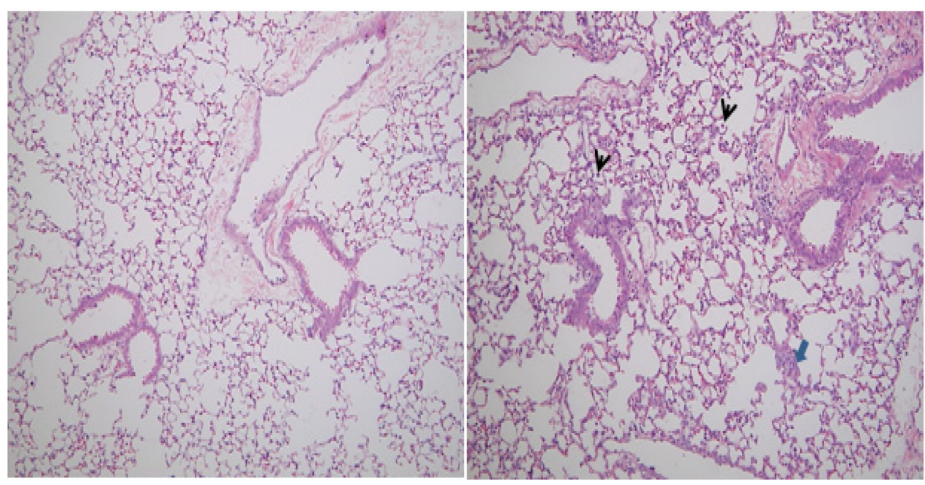

(C)

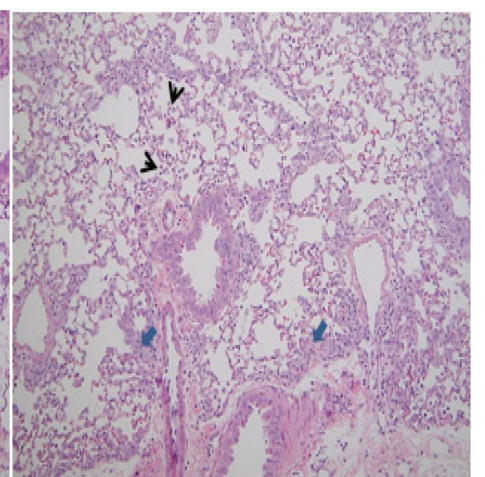

Fig. 3. Histopathologic changes in lung sections from mice treated with BLM and carbon nanoparticles. All samples were stained with H\&E and are shown at $\times 100$ magnification. (A) VC (saline + clean air), (B) BC (BLM + clean air), (C) BLM exposed (BLM + CBNPs). The black arrow highlights inflammatory cell infiltration, and the blue arrow highlights epithelial cell hyperplasia.

Table 1. Results of histopathologic examinations of lung sections

\begin{tabular}{|c|c|c|c|c|c|c|}
\hline \multirow{2}{*}{ Group } & \multicolumn{6}{|c|}{ Observation } \\
\hline & Animal & I & II & III & IV & $\mathrm{V}$ \\
\hline \multirow{2}{*}{ Control group (VC) } & Inflammatory cell infiltration & - & - & - & - & - \\
\hline & Epithelial cell hyperplasia & - & - & - & - & - \\
\hline \multirow{2}{*}{ BLM control group (BC) } & Inflammatory cell infiltration & 1 & 1 & 1 & 2 & 1 \\
\hline & Epithelial cell hyperplasia & 1 & 1 & 1 & 2 & 1 \\
\hline \multirow{2}{*}{ BLM exposed group (BLM+CBNPs) } & Inflammatory cell infiltration & 2 & 3 & 2 & 2 & 3 \\
\hline & Epithelial cell hyperplasia & 1 & 2 & 2 & 2 & 3 \\
\hline
\end{tabular}

-: examined but not observed, 1: minimal, 2: mild, 3: moderate. 
Table 2. Total cell counts in BAL fluid

\begin{tabular}{lc}
\hline \hline \multicolumn{1}{c}{ Group } & (Total cells $/ \mathrm{ml}) \times 10^{6}$ \\
\hline Control group (VC) & $0.262 \pm 0.059$ \\
BLM control group (BC) & $0.954 \pm 0.187$ \\
BLM exposed group (BLM + CBNPs) & $0.977 \pm 0.075$ \\
\hline
\end{tabular}

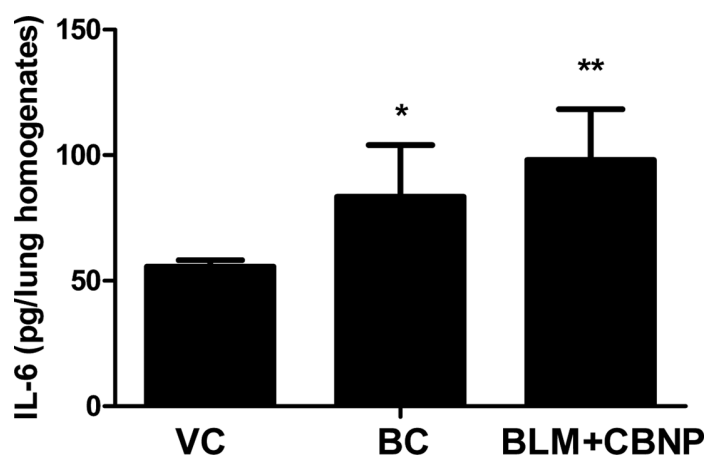

Fig. 4. IL-6 levels in lung tissue. The cytokine levels were analyzed by ELISA and expressed as pg/lung homogenate. Values are the mean $\pm \mathrm{SE}, \mathrm{n}=5 .{ }^{*} p<0.05$ and ${ }^{* *} p<0.01$, compared to the VC group.

(A)

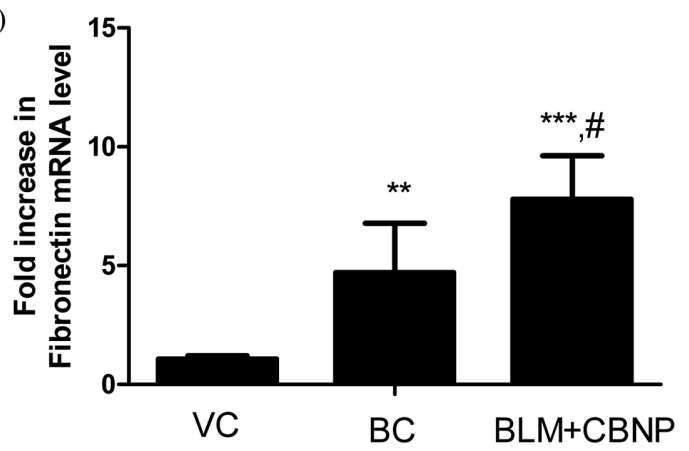

(B)

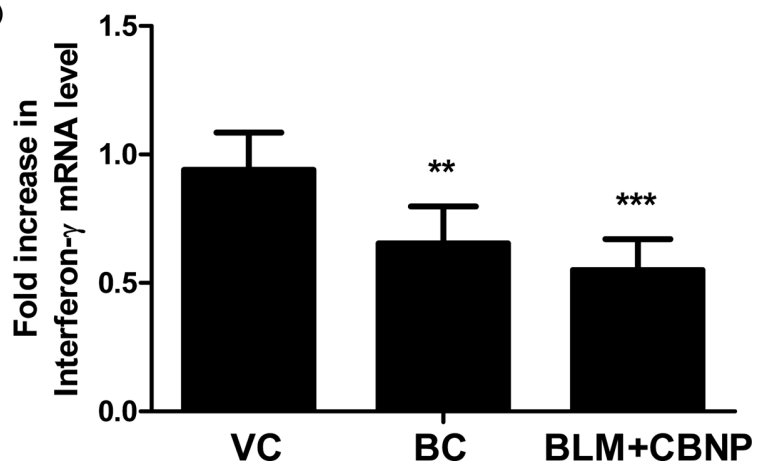

Fig. 5. Expression levels of (A) fibronectin and (B) IFN- $\gamma$ mRNAs in lung homogenates. Values are the mean $\pm \mathrm{SE}, \mathrm{n}=6$. $^{* *} p<$ 0.01 and ${ }^{* * *} p<0.001$, compared to the VC group. \# $p<0.05$, compared to $\mathrm{BC}$ group.

cytokine levels in lung tissue homogenates. We found that the expression of IL-6 was significantly increased in the BLM control and BLM exposed groups compared to the
(A)

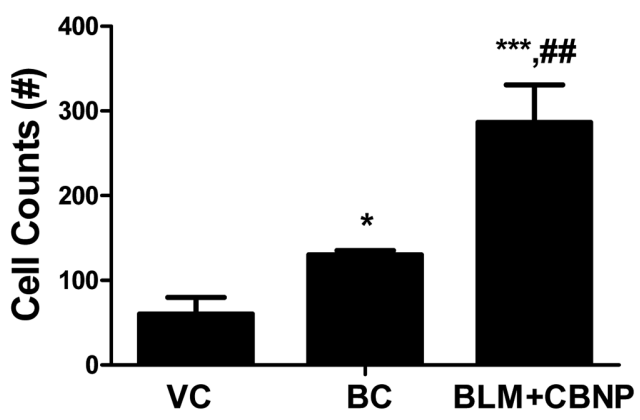

(B)

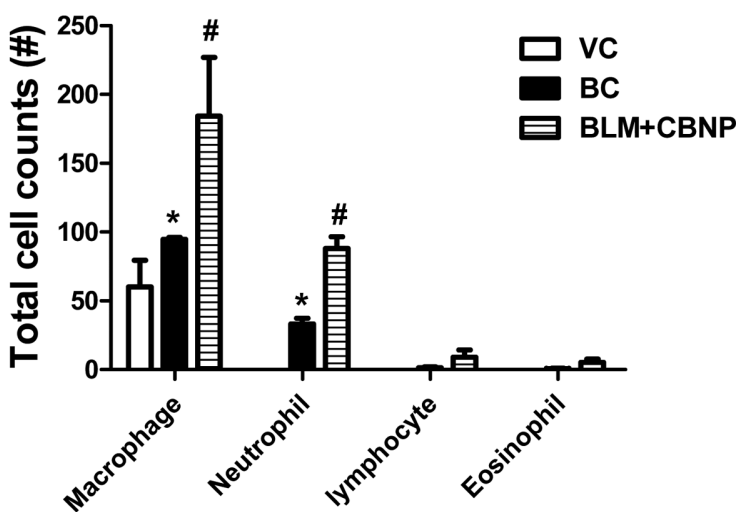

Fig. 6. Total (A) and differential (B) inflammatory cell count of macrophage, neutrophil, lymphocyte, and eosinophil. Values are the mean $\pm \mathrm{SE}, \mathrm{n}=3 .{ }^{*} p<0.05$ and ${ }^{* * *} p<0.001$ compared to the VC group. \# $p<0.001$ and \#\# $p<0.01$, compared to $\mathrm{BC}$ group.

control group (Fig. 4). There did not appear to be a significant difference in cytokine expression between the BLM control and BLM exposed groups (Fig. 5).

The expression of mRNAs coding for genes related to fibrosis and inflammation was also assessed in lung homogenates. We found that the level of fibronectin (FN) transcripts was significantly increased in the BLM control and in the BLM exposed group compared to the control (VC) group. Importantly, FN expression was significantly higher in the lungs from BLM-treated, CBNP-exposed group compared to the BLM control group (Fig. 6A). We also found that the expression of interferon- $\gamma$ (IFN- $\gamma$ ) transcripts was significantly reduced in animals from the BLM control group and the BLM exposed group compared to the control group (Fig. 6B).

\section{DISCUSSION}

Particulate matter in the air is a mixture of components like nitrates, sulfates, organic chemicals, metals, soil, and dust particles. Carbon makes up roughly $60 \%$ of particulate matter in the air, mainly in the form of organic carbon species and elemental carbon (17). Elemental carbon, sometimes referred to as black carbon or carbon black, is a primary pollutant formed in the combustion process (18). In 
general, the surface area of inhaled particulates is more determinative of their toxicity than their size, and smaller particles tend to have a larger relative surface area. Accordingly, it is known that nanoparticles can penetrate deep into the respiratory tract during breathing and thereby cause significant respiratory pathologies.

As a model for understanding the inhalation toxicity of ultrafine particles, we evaluated the effect of aerosolized carbon black nanoparticles (CBNPs) in a BLM-induced pulmonary fibrosis model in mice. Thus far, the pulmonary effects of nanoparticles have primarily been investigated by intratracheal administration. Herein, we utilized a novel aerosolization method to deliver nanoparticles via inhalation exposure through the nose, which more closely simulates human nanoparticle exposure. BLM induced model in this study is an established model from our previous study which showed pulmonary inflammatory response with $1 \mathrm{mg} /$ $\mathrm{kg}$ of bleomycin as an optimum dose (19).

BLM instilled mice showed decrease in body weight compared to control group. All groups also showed body weight decrease after inhalation of clean air or CBNP, which showed no test material-related change in this result. This body weight decrease is related to holding-induced stress. Changes in body weight after stress are well documented (20), restraint stress also have shown food intake decrease and body weight gain suppression (21). IL-6 has been shown to modulate chemokine expression, activate neutrophil, and stimulate B cell after bleomycin challenge (22). We observed increasing trend in IL-6 after CBNP exposure in BLM model compared to BLM control group. This increase of IL-6 level showed that CBNP aggravate inflammation occurred in BLM model. Fibronectin expression after CBNP exposure was also significantly elevated compared to BLM control group. Fibronectin is a profibrotic marker (23), which accumulates in alveolar tissue during early inflammatory phase of the BLM-induced lung injury (24). Furthermore, fibronectin has been shown to be increased in the presence of TGF- $\beta$, the key factor involved in BLM-induced pulmonary fibrosis $(25,26)$. In BLM model, fibrosis is occurred after repair of severe inflammation. With the increase of fibronectin observed after CBNP exposure in BLM model, we estimates severe inflammation has happened. IFN- $\gamma$ has been shown as an inhibitory modulator that limits fibroblasts proliferation, differentiation and collagen synthesis by inhibiting TGF- $\beta$ expression and activity (27). Expression of IFN- $\gamma$, a Th1 cytokine, has been observed to be decreased in bleomycin-induced pulmonary fibrosis in mice (28). This was also observed in cystic fibrosis (CF) patients with deficiency in IFN- $\gamma$ mRNA expression (29). We also observed decreasing trend of IFN- $\gamma$ after CBNP exposure in BLM model compared to BLM control group, which support our data that CBNP exposure aggravate inflammation leading to fibrosis occurred in BLM model. The number of total cells in BAL fluid tended to increase after CBNP exposure in BLM model, but no significance. We also observed increased of inflammation and hyperplasia by CBNP exposure, supported by elevation of macrophage and neutrophil number. Macrophage and neutrophil chemotactic activity has been shown to be significantly elevated in animal post-bleomycin injury (30).

The literature data describing the effects of carbon black inhalation exposure in animals is variable. Niwa et al. evaluated the effects of 4 weeks of carbon black exposure in rats and found that the exposure increased the expression of monocytes chemotactic protein-1, IL-6, and C-reactive protein, which are indicative of inflammation (31). They did not, however, observe alveolar inflammation or fibrosis. Based on that finding, we speculate the inflammatory response to carbon black in the lungs in their study was relatively mild. Adamson and Prieditis reported that CBNPs administered 4 days after BLM instillation remained in the lungs for an extended period of time (32). Even so, the BLM-induced fibrosis was not worsened by CBNP exposure. Still another study reported that intratracheal instillation of BLM caused inflammation and fibrosis, but co-administration of carbon did not worsen inflammation or fibrosis (12). In a contrasting study, carbon black was shown to be an accelerator and/or cofactor of BLM in respiratory disease or in abnormal lungs $(12,32)$. Specifically, Inoue et al. showed that $56 \mathrm{~nm}$ CBNPs aggravated porcine pancreatic elastase-induced pulmonary emphysema in mice, with evidence of increased IL-6 and interferon- $\gamma$ expression and clear histopathological symptoms.

This inconsistency of the literature with respect to whether CBNPs exacerbate lung disease may reflect differences among animal strains and/or species, pathological conditions, or the methods of CBNP exposure (route, dose, timing, duration, and/or end-point) $(33,34)$. The fact that we did not observe a significant pathologic change after coadministration of bleomycin and CBNPs may be due to the low CBNP concentration or short exposure time. It will therefore be important for future studies to determine whether increased concentrations or exposure times leads to more marked pathological differences.

Nanoparticle exposure via inhalation is known to be an important environmental risk factor for multiple lung inflammatory diseases like COPD, asthma, and allergy. It is useful to consider the human equivalence of the exposures delivered in our study. An estimate of the total dose delivered by inhalation can be derived from the following formula (35):

$$
\begin{aligned}
& \text { Delivered dose }\left(\frac{\mathrm{mg}}{\mathrm{kg}}\right) \\
& =\frac{\begin{array}{l}
\text { Respiratory Minute Volume }(\mathrm{L} / \mathrm{min}) \times \text { duration }(\mathrm{min}) \\
\text { Body weight }(\mathrm{kg})
\end{array}}{}
\end{aligned}
$$

Based on this formula, we can extrapolate that the 4-hr 
CBNP dose delivered to mice $\left(12.5 \mu \mathrm{g} / \mathrm{m}^{3}\right)$ is roughly equivalent to $\sim 130 \mu \mathrm{g} / \mathrm{m}^{3}$ exposure of the same duration in humans. Atmospheric carbon black emissions are quantified as a quantity of particles of $\leq 2.5$ microns (PM 2.5). There have been reported incidents wherein PM 2.5 concentrations reached $328 \mu \mathrm{g} / \mathrm{m}^{3}$ (36). A recent study in Korea also revealed that the average PM 2.5 level is $27.2 \mu \mathrm{g} / \mathrm{m}^{3}$ (37), and a broadcast of Korea reported that PM 2.5 levels were above $100 \mu \mathrm{g} / \mathrm{m}^{3}$ in early 2014. In addition, a well-designed multi-city study reported that the increase of daily mortality due to PM 2.5 was 3 times greater than that due to PM 10 (38). That study also reported a trend of increased health problems even when PM 2.5 levels were below $15 \mu \mathrm{g} / \mathrm{m}^{3}$, although the difference was not statistically significant. Thus, it is now thought that even lower PM 2.5 exposure levels can be problematic and merit further evaluation.

Herein, a brief and acute exposure study identified some signals that CBNPs aggravate lung inflammation in BLMinduced pulmonary fibrosis in mice. The results suggest that ultrafine particle could worsen lung inflammation in humans, particularly in susceptible persons with chronic lung diseases including fibrosis. It is likely that the effect would be even more significant when the particle exposure is chronic. These results underscore the need for more thorough and continued evaluation of the impact of ultrafine particle exposure on respiratory health.

\section{ACKNOWLEDGEMENT}

This work was supported by Utilization Technology Development of Research Equipments, S2060855 funded by the Small and Medium Business Administration (SMBA, Korea).

\section{REFERENCES}

1. Chiu, K.H., Lee, W.L., Chang, C.C., Chen, S.C., Chang, Y.C., Ho, M.N., Hsu, J.F. and Liao, P.C. (2010) A label-free differential proteomic analysis of mouse bronchoalveolar lavage fluid exposed to ultrafine carbon black. Anal. Chim. Acta, 673, 160-166.

2. Simkó, M. and Mattsson, M.O. (2010) Risks from accidental exposures to engineered nanoparticles and neurological health effects: a critical review. Part. Fibre Toxicol., 7, 42.

3. Sager, T.M. and Castranova, V. (2009) Surface area of particle administered versus mass in determining the pulmonary toxicity of ultrafine and fine carbon black: comparison to ultrafine titanium dioxide. Part. Fibre Toxicol., 6, 15.

4. Hubbs, A.F., Mercer, R.R., Benkovic, S.A., Harkema, J., Sriram, K., Schwegler-Berry, D., Goravanahally, M.P., Nurkiewicz, T.R., Castranova, V. and Sargent, L.M. (2011) Nanotoxicology--a pathologist's perspective. Toxicol. Pathol., 39, 301-324.

5. Lin, W., Huang, W., Zhu, T., Hu, M., Brunekreef, B., Zhang, Y., Liu, X., Cheng, H., Gehring, U., Li, C. and Tang, X. (2011) Acute respiratory inflammation in children and black carbon in ambient air before and during the 2008 Beijing Olympics. Environ. Health Perspect., 119, 1507-1512.

6. Ramage, L. and Guy, K. (2004) Expression of C-reactive protein and heat-shock protein-70 in the lung epithelial cell line A549, in response to PM10 exposure. Inhalation Toxicol., 16, 447-452.

7. Donaldson, K., Stone, V. and MacNee, W. (1999) The toxicology of ultrafine particles (In: Maynard RL, Howard CV, Eds). Particulate matter: properties and effects upon health. Oxford: Bios Scientific.

8. Tong, H., McGee, J.K., Saxena, R.K., Kodavanti, U.P., Devlin, R.B. and Gilmour, M.I. (2009) Influence of acid functionalization on the cardiopulmonary toxicity of carbon nanotubes and carbon black particles in mice. Toxicol. Appl. Pharmacol., 239, 224-232.

9. Donaldson, K., Stone, V., Clouter, A., Renwick, L. and MacNee, W. (2001) Ultrafine particles. Occup. Environ. Med., 58, 211-216.

10. Bourdon, J.A., Halappanavar, S., Saber, A.T., Jacobsen, N.R., Williams, A., Wallin, H., Vogel, U. and Yauk, C.L. (2012) Hepatic and pulmonary toxicogenomic profiles in mice intratracheally instilled with carbon black nanoparticles reveal pulmonary inflammation, acute phase response, and alterations in lipid homeostasis. Toxicol. Sci., 127, 474-484.

11. Tomimori, Y., Muto, T., Saito, K., Tanaka, T., Maruoka, H., Sumida, M., Fukami, H. and Fukuda, Y. (2003) Involvement of mast cell chymase in bleomycin-induced pulmonary fibrosis in mice. Eur. J. Pharmacol., 478, 179-185.

12. Decologne, N., Wettstein, G., Kolb, M., Margetts, P., Garrido, C., Camus, P. and Bonniaud, P. (2010) Bleomycin induces pleural and subpleural fibrosis in the presence of carbon particles. Eur. Respir. J., 35, 176-185.

13. Zhou, X.M., Zhang, G.C., Li, J.X. and Hou, J. (2007) Inhibitory effects of Hu-qi-yin on the bleomycin-induced pulmonary fibrosis in rats. J. Ethnopharmacol., 111, 255-264.

14. Kamata, H., Tasaka, S., Inoue, K., Miyamoto, K., Nakano, Y., Shinoda, H., Kimizuka, Y., Fujiwara, H., Ishii, M., Hasegawa, N., Takamiya, R., Fujishima, S., Takano, H. and Ishizaka, A. (2011) Carbon black nanoparticles enhance bleomycininduced lung inflammatory and fibrotic changes in mice. Exp. Biol. Med. (Maywood), 236, 315-324.

15. Li, Y.J., Azuma, A., Usuki, J., Abe, S., Matsuda, K., Sunazuka, T., Shimizu, T., Hirata, Y., Inagaki, H., Kawada, T., Takahashi, S., Kudoh, S. and Omura, S. (2006) EM703 improves bleomycin-induced pulmonary fibrosis in mice by the inhibition of TGF-beta signaling in lung fibroblasts. Respir. Res., 7, 16.

16. Vesterdal, L.K., Folkmann, J.K., Jacobsen, N.R., Sheykhzade, M., Wallin, H., Loft, S. and Moller, P. (2010) Pulmonary exposure to carbon black nanoparticles and vascular effects. Part. Fibre Toxicol., 7, 33.

17. Gu, J., Bai, Z., Liu, A., Wu, L., Xie, Y., Li, W., Dong, H. and Zhang, X. (2010) Characterization of Atmospheric Organic Carbon and Element Carbon of $\mathrm{PM}_{2.5}$ and $\mathrm{PM}_{10}$ at Tianjin, China. Aerosol Air Qual. Res., 10, 167-176.

18. Seinfeld, J.H. and Pandis, S.N (1998) Atmospheric chemistry and physics: From air pollution to climate change, John Wiley, New York, pp. 1-1232.

19. Kim, S.N., Lee, J., Yang, H.S., Cho, J.W., Kwon, S., Kim, 
Y.B., Her, J.D., Cho, K.H., Song, C.W. and Lee, K. (2010) Dose-response Effects of Bleomycin on Inflammation and Pulmonary Fibrosis in Mice. Toxicol. Res., 26, 217-222.

20. Rybkin, I.I., Zhou, Y., Volaufova, J., Smagin, G.N., Ryan, D.H. and Harris, R.B. (1997) Effect of restraint stress on food intake and body weight is determined by time of day. Am. J. Physiol., 273, 1612-1622.

21. Harris, R.B., Zhou, J., Youngblood, B.D., Rybkin, I.I., Smagin, G.N. and Ryan, D.H. (1998) Effect of repeated stress on body weight and body composition of rats fed low- and highfat diets. Am. J. Physiol., 275, R1928-1938.

22. Smith, R.E., Strieter, R.M., Phan, S.H., Lukacs, N. and Kunkel, S.L. (1998) TNF and IL-6 mediate MIP-1alpha expression in bleomycin-induced lung injury. J. Leukocyte Biol., 64, 528-536.

23. Moeller, A., Ask. K., Warburton, D., Gauldie, J. and Kolb, M. (2008) The bleomycin animal model: a useful tool to investigate treatment options for idiopathic pulmonary fibrosis? Int. J. Biochem. Cell Biol., 40, 362-382.

24. Hernnäs, J., Nettelbladt, O., Bjermer, L., Särnstrand, B., Malmström, A. and Hällgren, R. (1992) Alveolar accumulation of fibronectin and hyaluronan precedes bleomycininduced pulmonary fibrosis in the rat. Eur. Respir. J., 5, 404410

25. Chen, Y.L., Zhang, X., Bai, J., Gai, L., Ye, X.L., Zhang, L., Xu, Q., Zhang, Y.X., Xu, L., Li, H.P. and Ding, X. (2013) Sorafenib ameliorates bleomycin-induced pulmonary fibrosis: potential roles in the inhibition of epithelial-mesenchymal transition and fibroblast activation. Cell Death Dis., 4, e665.

26. Zhao, J., Shi, W., Wang, Y.L., Chen, H., Bringas, P, Jr., Datto, M.B., Frederick, J.P., Wang, X.F. and Warburton, D. (2002) Smad3 deficiency attenuates bleomycin-induced pulmonary fibrosis in mice. Am. J. Physiol. Lung Cell. Mol. Physiol., 282, L585-593.

27. Segel, M.J., Izbicki, G., Cohen, P.Y., Or, R., Christensen, T.G., Wallach-Dayan, S.B. and Breuer, R. (2003) Role of interferon-gamma in the evolution of murine bleomycin lung fibrosis. Am. J. Physiol. Lung Cell. Mol. Physiol., 285, L12551262.

28. Kikuchi, N., Ishii, Y., Morishima, Y., Yageta, Y., Haraguchi, N., Itoh, K., Yamamoto, M. and Hizawa, N. (2010) Nrf2 pro- tects against pulmonary fibrosis by regulating the lung oxidant level and Th1/Th2 balance. Respir. Res., 11, 31.

29. Kushwah, R., Gagnon, S. and Sweezey, N.B. (2014) T cell unresponsiveness in a pediatric cystic fibrosis patient: a case report. Allergy Asthma Clin. Immunol., 10, 2.

30. Izbicki, G., Segel, M.J., Christensen, T.G., Conner, M.W. and Breuer, R. (2002) Time course of bleomycin-induced lung fibrosis. Int. J. Exp. Pathol., 83, 111-119.

31. Niwa, Y., Hiura, Y., Sawamura, H. and Iwai, N. (2008) Inhalation exposure to carbon black induces inflammatory response in rats. Circ. J., 72, 144-149.

32. Adamson, I.Y. and Prieditis, H.L. (1995) Response of mouse lung to carbon deposition during injury and repair. Environ. Health Perspect., 103, 72-76.

33. Elsaesser, A. and Howard, C.V. (2012) Toxicology of nanoparticles. Adv. Drug Delivery Rev., 64, 129-137.

34. Inoue, K., Yanagisawa, R., Koike, E., Nakamura, R., Ichinose, T., Tasaka, S., Kiyono, M. and Takano, H. (2011) Effects of carbon black nanoparticles on elastase-induced emphysematous lung injury in mice. Basic Clin. Pharmacol. Toxicol., 108, 234-240.

35. Alexander, D.J., Collins, C.J., Coombs, D.W., Gilkison, I.S., Hardy, C.J., Healey, G., Karantabias, G., Johnson, N., Karlsson, A., Kilgour, J.D. and McDonald, P. (2008) Association of Inhalation Toxicologists (AIT) working party recommendation for standard delivered dose calculation and expression in non-clinical aerosol inhalation toxicology studies with pharmaceuticals. Inhalation Toxicol., 20, 1179-1189.

36. Begum, B.A., Hossain, A., Nahar, N., Markwitz, A. and Hopke, P.K. (2012) Organic and Black Carbon in PM2.5 at an Urban Site at Dhaka, Bangladesh. Aerosol Air Qual. Res., 12, 1062-1072.

37. Won, S.R., Lim, J.Y., Shim, I.K., Kim, E.J., Choi, A.R., Han, J.S. and Lee, W.S. (2012) Characterization of $\mathrm{PM}_{2.5}$ and $\mathrm{PM}_{10}$ concentration distribution at public facilities in Korea. $J$. Korean Soc. Indoor Environ., 9, 229-238.

38. Franklin, M., Zeka, A. and Schwartz, J. (2007) Association between PM2.5 and all-cause and specific-cause mortality in 27 US communities. J. Exposure Sci. Environ. Epidemiol., 17, 279-287. 